\title{
The CREST-2 experience with the evolving challenges of COVID-19
}

\section{A clinical trial in a pandemic}

\author{
James F. Meschia, MD, Kevin M. Barrett, MD, Robert D. Brown, Jr., MD, Tanya N. Turan, MD, \\ Virginia J. Howard, PhD, Jenifer H. Voeks, PhD, Brajesh K. Lal, MD, George Howard, DrPH, and \\ Thomas G. Brott, MD
}

Neurology ${ }^{\circledR}$ 2020;95:29-36. doi:10.1212/WNL.0000000000009698

\section{Abstract}

The coronavirus disease 2019 pandemic has disrupted the lives of whole communities and nations. The multinational multicenter National Institute of Neurological Disorders and Stroke Carotid Revascularization and Medical Management for Asymptomatic Carotid Stenosis Trial stroke prevention trial rapidly experienced the effects of the pandemic and had to temporarily suspend new enrollments and shift patient follow-up activities from in-person clinic visits to telephone contacts. There is an ethical obligation to the patients to protect their health while taking every feasible step to ensure that the goals of the trial are successfully met. Here, we describe the effects of the pandemic on the trial and steps that are being taken to mitigate the effects of the pandemic so that trial objectives can be met.

\section{Introduction}

Coronavirus disease 2019 (COVID-19) has spread rapidly, inflicted considerable morbidity and mortality, and disrupted society on a global level. ${ }^{1,2}$ On April 14, 2020, the Institute for Health Metrics and Evaluation projected that peak resource utilization had occurred on April 10 , at which time it was estimated that 56,831 hospital beds, 15,164 intensive care unit (ICU) beds, and 13,851 ventilators were needed for patients with COVID-19; 68,841 COVID-19 deaths are projected by August 4, 2020. ${ }^{3}$ These increases in the burden on the health care system make elective contacts with health care providers inappropriate, including clinic visits associated with the conduct of many clinical trials. In addition, investigators in trials are obligated to consider the potential increased patient exposure to the COVID-19 virus associated with research clinic visits, particularly in trials studying the elderly who are at a higher risk from the virus. Because about $25 \%$ of persons with COVID-19 are asymptomatic carriers, reducing unnecessary clinic visits is important for reducing the risk of contamination and infecting health care workers. Finally, elective procedures that are part of clinical trial protocols must be postponed to allow the health care system to respond adequately to the additional burden from the pandemic.

Although stopping a trial in response to these immense challenges may be tempting, doing so would violate the moral obligation made to those patients already randomized. ${ }^{4}$ Most people support the altruistic rationale underlying clinical trials, i.e., in the intrinsic value of increasing scientific knowledge and helping future patients. ${ }^{5}$ As such, the ethical investigator should always strive to complete the trial regardless of challenges including a pandemic.

The inability to do business as usual, coupled with the moral obligation to complete the trial in a manner to provide a valid comparison of treatment efficacy, requires radical but thoughtful adaptation of methods and approaches. Herein, we describe the actions taken by the Carotid

\author{
Correspondence \\ Dr. Meschia, MD \\ meschia.james@mayo.edu
}

\section{COVID-19 Resources}

For the latest articles, invited commentaries, and blogs from physicians around the world NPub.org/COVID 19

\footnotetext{
From the Department of Neurology (J.F.M., K.M.B., T.G.B.), Mayo Clinic, Jacksonville, FL; Department of Neurology (R.D.B.), Mayo Clinic, Rochester, MN; Department of Neurology (T.N.T., J.H.V.), Medical University of South Carolina, Charleston; Department of Epidemiology (V.J.H.) and Department of Biostatistics (G.H.), University of Alabama at Birmingham; Department of Surgery (B.K.L.), University of Maryland, College Park.

Go to Neurology.org/N for full disclosures. Funding information and disclosures deemed relevant by the authors, if any, are provided at the end of the article.
} 


\section{Glossary}

$\mathrm{ACE}=$ angiotensin-converting enzyme; $\mathbf{A R B}=$ angiotensin II type I receptor blocker; $\mathbf{C A S}=$ carotid artery stenting; $\mathbf{C C C}=$ Clinical Coordinating Center; CEA = carotid endarterectomy; COVID-19 = coronavirus disease 2019; CREST-2 = Carotid Revascularization and Medical Management for Asymptomatic Carotid Stenosis Trial; DMS = data management system; ICU = intensive care unit; IMM = intensive medical management; PI = principal investigator; PSS-4 = Perceived Stress Scale 4; SDCC $=$ Statistical and Data Management Center.

Revascularization and Medical Management for Asymptomatic Carotid Stenosis Trial (CREST-2; NCT02089217) investigators to continue the trial in the face of the challenges introduced by the COVID-19 virus pandemic.

\section{Methods}

CREST-2 is an ongoing pair of parallel randomized trials testing interventions to prevent ischemic stroke in the presence of severe asymptomatic carotid artery stenosis. One trial randomizes patients to carotid endarterectomy (CEA) plus intensive medical management (IMM) or IMM alone. The second trial randomizes patients to carotid artery stenting (CAS) plus IMM or IMM alone. ${ }^{6}$ The trial has 111 actively enrolling centers across the United States, with 5 additional centers in Canada and Spain. The first patient was enrolled on December 10, 2014. A total of $67 \%(1,653 / 2,480)$ of the target recruitment goal has been achieved as of March 25, 2020, with enrollments having occurred in 131 centers in the United States, Canada, and Spain. Patients are followed for stroke end points up to 4 years, with periodic in-person clinic visits. Unique aspects of the trial include centralized IMM and telephone assessment of cognitive function. In-person visits allow monitoring of risk factors and adjustment of medications as needed to achieve systolic blood pressure and serum low-density lipoprotein cholesterol targets.

\section{Initial effect on enrollment}

The typical patient eligible for or enrolled in CREST-2 may be at an increased risk of morbidity and mortality due to COVID-19. Half of all CREST-2 patients are aged 70 years or older (median, 70 years; interquartile range [IQR], 65-75 years), and there is a high prevalence of risk factors for cardiovascular disease (36.9\% are patients with diabetes; $85.9 \%$, patients with hypertension; and $91.5 \%$, patients with dyslipidemia). The early experience in Italy with COVID-19 shows the case fatality rate to be substantially higher for older individuals, ranging from $<4 \%$ for individuals younger than 70 years to $>12 \%$ for individuals aged 70 years and older. ${ }^{7}$ Likewise, the Centers for Disease Control and Prevention (CDC) reported that among those infected with the virus, mortality ranges from $10 \%$ to $27 \%$ for those aged 85 years or older, $3 \%-11 \%$ for those aged 65 to 84 years, and $1 \%-3 \%$ for those aged 55-64 years. ${ }^{8}$ Hypertension and diabetes mellitus are common comorbidities among patients with COVID-19. These same risk factors have been shown to be associated with death and poor outcomes among those infected with COVID-
$19 .^{10}$ Furthermore, SARS-CoV-2 binds to target cells through angiotensin-converting enzyme 2 (ACE2). ${ }^{11}$ Some investigators have suggested that use of ACE inhibitors and angiotensin II type I receptor blockers (ARBs) may increase the risk of severe COVID-19 through increasing expression of ACE2. ${ }^{9}$ Other investigators are in the process of testing ARBs in placebo-controlled trials as a treatment for COVID-19 (NCT04311177; NCT04312009); ACE inhibitors and ARBs are both recommended as options in accordance with the CREST-2 IMM protocol to control systolic blood pressure to the trial goal of $<130 \mathrm{~mm} \mathrm{Hg}$, with $73.2 \%$ of the patients with hypertension in the study currently treated with either an ACE inhibitor or an ARB. Currently, the AHA recommends that patients taking ACE inhibitors and ARBs who contract COVID-19 should continue treatment, unless otherwise advised by their physician. ${ }^{12}$

COVID-19 has the potential to radically curtail recruitment into CREST-2 and other clinical trials until the pandemic passes. It is hoped that social distancing and self-quarantining will flatten and delay the peak of the curve, reducing the likelihood that ICUs will be overwhelmed and will buy time to develop effective pharmacologic therapies. ${ }^{13,14}$ Clinical research coordinators serve as a resource for patients and families to discuss study procedures and to answer questions regarding trial participation. Often, the complex and personal decision to enroll in a clinical trial and participate in protocolspecified visits is influenced by the rapport and trust developed between research team members and patients. Such relationships may be challenging to establish when working remotely. Further compounding the challenge of recruitment during the pandemic are decisions by many practices to limit outpatient office visits to urgent conditions. Outpatient referrals of patients with asymptomatic carotid stenosis to surgical practices have historically been a high-yield source of patients eligible for CREST-2 participation.

Other factors that may adversely affect recruitment and retention of patients during the COVID-19 pandemic include the adverse psychological effects on health care workers from managing infected patients. In Wuhan, China, hundreds of health care workers have received treatment from psychological intervention teams deployed during the COVID-19 crisis to manage symptoms of anxiety, depression, and fear. ${ }^{15}$

The COVID-19 pandemic has resulted in cancelation, sometimes under governmental instruction, of elective procedures at many institutions across the United States and 
beyond. For patients with asymptomatic carotid stenosis, the American Heart Association considers CEA to be a grade IIa recommendation and CAS to be a grade IIb recommendation. Although revascularization may result in a large relative reduction in stroke risk, the absolute reduction in risk is anticipated to be low. As such, we believe that it is reasonable for institutions to regard revascularization in the CREST-2 target population as elective. The aforementioned factors culminated in a decision on March 24, 2020, to temporarily suspend new CREST-2 enrollments at all sites. We will work closely with the clinical sites, the central Investigational Review Board (cIRB), and the National Institute of Neurological Disorders and Stroke staff to open and complete recruitment at an appropriate time where patient safety is not endangered.

\section{Steps to mitigate the effects of COVID-19 on follow-up}

COVID-19 has caused us to adapt our process of following patients in CREST-2. The trial was designed for in-person clinic follow-up visits, with telephone visits permitted by the protocol only if the in-person assessments could not be achieved. However, early in the US epidemic, institutional restrictions to limit nonessential visits at the clinical sites fed a substantial increase in the requests from research coordinators to follow patients by telephone. Before the pandemic, we had a process that required individual sites to have approval from the principal investigators (PIs) at the Clinical Coordinating Center (CCC) to substitute a telephone followup for the scheduled in-person examination. Once this permission was obtained, the staff at the Statistical and Data Management Center (SDCC) provided override codes for the in-person collection of data, permitting the structured telephone follow-up to be conducted. Data collected through this telephone contact included interval medical and surgical histories, stroke symptoms questionnaire data, ${ }^{16}$ and modified Rankin Scale ${ }^{17}$; however, telephone visits could not include assessments requiring in-person examination of the patient or the collection of laboratory data. Similar to the in-person assessment, when patients reported having had an interval medical evaluation for suspected stroke or TIA, medical records would be secured and adjudicated as they would for face-to-face clinic visits.

Telemedicine is an alternative and viable approach to mitigate loss to follow-up for patients unable to complete face-to-face clinic visits. Telemedicine can facilitate collection of observation-based physical examination findings that cannot be adequately assessed by telephone. In addition, interventions and outcomes that are best delivered or obtained under direct supervision are uniquely suited to telemedicine encounters when face-to-face encounters are not feasible or safe. Although telemedicine may be adopted into certain neurologic clinical trial infrastructures, the CREST-2 experience with a pilot of in home video blood pressure measurements found barriers to adoption by participants including lack of access to internet/Wi-Fi in rural areas, lack of home video technology, and age-related difficulties with technology.
With the pandemic, the CCC recognized that it would soon be overwhelmed with requests for telephone contacts, either due to lack of staffing at sites, quarantining, or social distancing of patients. It became apparent that practically every request for a remote assessment would ultimately be approved given site restrictions on face-to-face visits, making the need to obtain approval a needless burden to staff at the clinical site, and investigators and staff at the CCC and SDCC. Thus, on March 13 , 2020, we issued a policy change to allow for telephone follow-ups on a routine basis for all patients and plan to rereview the policy on a monthly basis, so the clinical sites can revert to clinic follow-up once appropriate.

CREST-2 had invested heavily in developing an FDAcompliant data management system (DMS) that tightly enforces the protocol, including programmed skip patterns ensuring that proper approval for conducting a telephone follow-up assessment had been assured. This FDA compliance also includes layers of documentation and testing of any changes to the DMS, introducing challenges to quickly change systems to allow the flexibility to more easily conduct remote follow-up assessments. The investigators and staff at the SDCC were responsible for considering changes that placed a minimal burden to the clinical center staff, changes that were needed to the programming rules, the actual programming of these changes, and the testing of the newly modified system. In addition, the study coordinators at the clinical sites had to be carefully trained in the methods and approaches for conducting a follow-up assessment, including the steps to move from conducting an in-person to a telephone follow-up. The staff at the CCC and SDCC were jointly responsible for retraining the clinical center staff at 111 clinical sites.

Telephone follow-up visits are not seen as equivalent to inperson clinic visits. Telephone follow-up does not currently allow for standardized reassessment of vascular risk factors, especially blood pressure and lipids. This makes active titration of pharmacologic therapies to achieve risk factor control targets more challenging. In addition to follow-up from the clinical centers, patients receive risk factor counseling via telephone from a commercial company (INTERVENT; Savannah, GA). Nonpharmacologic counseling through INTERVENT (e.g., smoking cessation and physical activity) is unaffected by the pandemic.

To gain better insight into how the COVID-19 situation was affecting local sites, the CCC developed and distributed an online survey to research coordinators and site PIs. The survey was designed to ascertain the effects of the pandemic on the conduct of clinical trials, with the CREST-2 trial as the case in point. A survey invitation was sent to 540 individuals at all 154 CREST-2 sites green-lighted to enroll patients (129 PIs and 411 study coordinators [many sites have 2 or more coordinators]). As of March 26, 2020, we have received responses from 110 sites (71.4\%), with 41 sites having more than 1 respondent $(37.2 \%)$. The total number of responses to 
Table 1 Results of survey of investigators and coordinators regarding the effects of COVID-19 on the CREST-2 trial

\begin{tabular}{ll}
\hline Answer choice & N (\%) \\
\hline $\begin{array}{l}\text { Q1. In response to the COVID-19 pandemic, what } \\
\text { institutional policy related to clinical trials has been } \\
\text { implemented with regard to (check all that apply): }\end{array}$ \\
\hline Follow-up visits & $127(80.89)$ \\
\hline Monitoring visits & $122(77.71)$ \\
\hline Travel & $109(69.43)$ \\
\hline Enrollment & $106(67.52)$ \\
\hline Teleworking & $90(56.96)$ \\
\hline Screening & $85(54.14)$ \\
\hline Treatment & $84(53.50)$ \\
\hline Other & $12(7.64)$ \\
\hline
\end{tabular}

Q2. How has the COVID-19 institutional policy affected your ability to screen research patients?

\begin{tabular}{lc}
\hline Strongly affected & $84(53.50)$ \\
\hline Moderately affected & $39(24.68)$ \\
\hline Not affected at all & $35(22.29)$
\end{tabular}

Q3. How has the COVID-19 institutional policy affected your ability to enroll research patients?

\begin{tabular}{ll}
\hline Strongly affected & $109(69.43)$ \\
\hline Moderately affected & $34(21.52)$ \\
\hline Not affected at all & $15(9.55)$ \\
\hline $\begin{array}{l}\text { Q4. How has the COVID-19 institutional policy affected } \\
\text { your ability to treat research patients? }\end{array}$ \\
\hline Strongly affected & $68(43.04)$ \\
\hline Moderately affected & $65(41.14)$ \\
\hline Not affected at all & $25(15.82)$ \\
\hline
\end{tabular}

Q5. How has the COVID-19 institutional policy affected your ability to conduct research follow-up visits?

\begin{tabular}{ll}
\hline Strongly affected & $78(49.37)$ \\
\hline Moderately affected & $66(41.77)$ \\
\hline Not affected at all & $14(8.86)$
\end{tabular}

Q6. How has the COVID-19 institutional policy affected your ability to participate in research monitoring visits?

\begin{tabular}{lc}
\hline Strongly affected & $108(68.35)$ \\
\hline Moderately affected & $38(24.05)$ \\
\hline Not affected at all & $12(7.59)$ \\
\hline
\end{tabular}

Q7. Do you have online access to CREST-2 source documents in your medical center's electronic medical record?

\begin{tabular}{lc}
\hline Yes & $111(77.62)$ \\
\hline No & $32(22.38)$ \\
\hline
\end{tabular}

Table 1 Results of survey of investigators and coordinators regarding the effects of COVID-19 on the CREST-2 trial (continued)

\begin{tabular}{ll}
\hline Answer choice & N (\%) \\
\hline $\begin{array}{l}\text { Q8. Have you been required to take on unplanned } \\
\text { added or different work activities (i.e., redeployed) } \\
\text { since the COVID-19 crisis? }\end{array}$ \\
\hline Yes & $64(44.76)$ \\
\hline No & $79(55.24)$ \\
\hline $\begin{array}{l}\text { Q9. Have employees been furloughed at your medical } \\
\text { center due to the COVID-19 crisis? }\end{array}$ \\
\hline Yes & $69(48.25)$ \\
\hline No & $74(51.75)$ \\
\hline
\end{tabular}

Abbreviations: CREST-2 = Carotid Revascularization and Medical Management for Asymptomatic Carotid Stenosis Trial; COVID-19 = coronavirus disease 2019

the survey has been 158, from 33 PIs and 125 study coordinators. More than $50 \%$ of respondents indicated that changes to institutional policy related to screening, enrollment, treatment, follow-up, monitoring visits, travel, and teleworking had been implemented in response to COVID-19 (table 1). The most frequently reported institutional policy change affected follow-up visits (81\%). Additional results indicating the magnitude of the effect on various clinical trial elements are summarized in table 1 .

We assessed global stress among research coordinators using the Perceived Stress Scale 4 (PSS-4), a simple, reliable, and valid instrument, with scores ranging from 0 (no stress) to 16 (extreme stress). ${ }^{18}$ The survey was first emailed on April 9, 2020, and re-emailed on April 10, 2020, to maximize response rate. The survey was conducted completely anonymously. Table 2 shows the responses for the 4 questions in the PSS-4. Nearly half of the coordinators stated that very often or fairly often (44\%), they felt that they could not control the events in their lives. However, most ( $80 \%)$ stated that they were very confident or fairly confident that they could handle their personal problems. About 1 in $6(16 \%)$ stated that difficulties were piling up so fast that fairly often or very often, they could not handle them. The mean (SD) PSS-4 was 6.54 (2.7), and the median (range) was 7 (0-14). A total of $13 \%$ had a PSS-4 score of $>9$ points.

The survey results indicate considerable variability at the CREST-2 site level, suggesting a need for more frequent CCC site communication to share ideas for COVID-19 problem solving. As part of standard site management, there are regular and ad hoc telephone and email communications among the CCC, SDCC, and the sites; these have increased substantially since the middle of March. The CCC holds monthly coordinator teleconferences that serve as a platform to keep study teams informed. On the March 17, 2020, 
teleconference, the anticipated effects of the COVID-19 on recruitment and patient follow-up were shared and discussed; 136 coordinators participated. The CCC announced the temporary suspension of the CREST-2 Low Enrollment Policy, a mechanism used to warn and motivate underperforming sites. Tactics for mitigation were also addressed. This teleconference demonstrated the need for more frequent communication. As of March 30, 2020, the CCC and SDCC leadership will initiate weekly coordinator teleconferences to facilitate communication and enhance partnership between the coordinating centers and sites. Similar teleconferences were held quarterly with the site PIs. These teleconferences will now be held monthly for the duration of the pandemic. CREST-2 had a planned annual research coordinators' meeting scheduled for May 6-8 in New Orleans, LA, but this meeting was postponed in response to US CDC recommendations. The annual meeting has been used to review and clarify key aspects of the protocol, recognize and celebrate successes in recruitment and retention, provide an update on the science of managing patients with asymptomatic carotid stenosis, and share plans for future ancillary or follow-on studies. Normally, announcement of a cancellation of a vital meeting like the annual coordinators' meeting would be met with a concurrent announcement of a rescheduling, but that has not been possible, given the current uncertainty regarding the end of the pandemic. Furthermore, return to normal in health care and clinical research may lag behind a drop in prevalence of the COVID-19 virus. CREST-2 also runs a separate annual site principal investigators' meeting. The next one is scheduled for December 5, 2020, but that may also need to be postponed because of uncertainties of the pandemic.

COVID-19 has also affected on-site monitoring visits. Policy changes at Mayo Clinic now prohibit domestic travel, making future in-person visits impossible. On March 20, 2020, we canceled our first scheduled monitoring visit (West Virginia University Medical) due to lack of access to staff and therefore access to source documentation. No further in-person monitoring visits will be possible until the end of the pandemic. Such visits are important for patient safety and clinical trial integrity. Rigorous monitoring is also required for CREST-2 and other clinical trials that are conducted under an FDA Investigational Device Exemption. Until in-person monitoring can be resumed, the CCC and SDCC have devised a plan for FDA-compliant remote monitoring. Sites are being categorized by their ability to conduct remote monitoring. Thirteen sites have been evaluated as to whether detailed remote monitoring can take place. Such monitoring will be feasible at 6 , and these remote monitoring visits have been scheduled. We have also developed an interim monitoring process, shifting our current monitoring paradigm from source data verification to quality control of current data. Monitors focus on protocol adherence, under reporting of protocol deviations, trial conduct, safety, data integrity, protocol compliance, and trends in data quality by site.
Table 2 Results of the Perceived Stress Scale 4 survey sent to all CREST-2 coordinators

\begin{tabular}{ll}
\hline Answer choice & N (\%) \\
\hline $\begin{array}{l}\text { Q1. In the last month, how often have you felt that you } \\
\text { were unable to control the important things in your life? }\end{array}$ \\
\hline Never & $6(4.20)$ \\
\hline Almost never & $14(9.79)$ \\
\hline Sometimes & $60(41.96)$ \\
\hline Fairly often & $42(29.37)$ \\
\hline Very often & $21(14.69)$ \\
\hline
\end{tabular}

Q2. In the last month, how often have you felt confident about your ability to handle your personal problems?

\begin{tabular}{ll}
\hline Very often & $46(32.17)$ \\
\hline Fairly often & $68(47.55)$ \\
\hline Sometimes & $25(17.48)$ \\
\hline Almost never & $4(2.80)$ \\
\hline Never & $0(0.00)$ \\
\hline
\end{tabular}

Q3. In the last month, how often have you felt that things were going your way?

\begin{tabular}{ll}
\hline Very often & $12(8.39)$ \\
\hline Fairly often & $53(37.06)$ \\
\hline Sometimes & $69(48.25)$ \\
\hline Almost never & $8(5.59)$ \\
\hline Never & $1(0.70)$ \\
\hline
\end{tabular}

Q4. In the last month, how often have you felt difficulties were piling up so high that you could not overcome them?

\begin{tabular}{lc}
\hline Never & $15(10.49)$ \\
\hline Almost never & $43(30.07)$ \\
\hline Sometimes & $62(43.36)$ \\
\hline Fairly often & $19(13.29)$ \\
\hline Very often & $4(2.80)$ \\
\hline
\end{tabular}

Abbreviation: CREST-2 = Carotid Revascularization and Medical Management for Asymptomatic Carotid Stenosis Trial.

\section{Tactics for future mitigation}

IMM is a crucial aspect of the study for all patients. Hence, efforts are underway to develop tactics for CREST-2 patients to continue to receive management for their primary risk factors (systolic blood pressure and low-density lipoprotein). For systolic blood pressure, we are exploring the option to enable patients to monitor their blood pressures from home to inform medication changes. The prepandemic protocol required office-based measuring, recording, and responding primarily to blood pressures measured by trained coordinators using a standardized automated blood pressure cuff (Omron HEM-705CP). As an alternative, we are considering 
Table 3 Problems created by the SARS-CoV-19 pandemic and possible solutions common to multicenter clinical trials involving neurologic disorders

\begin{tabular}{lll}
\hline Key element of a clinical trial & Problems & Possible solutions \\
\hline $\begin{array}{l}\text { Intervention (drug, procedure, and } \\
\text { behavior) }\end{array}$ & $\begin{array}{l}\text { Delivery and administration of drugs/device, especially } \\
\text { investigational drugs or device } \\
\text { Reduction in research staffing }\end{array}$ & $\begin{array}{l}\text { Consider drive-by medication pick-up or } \\
\text { administration } \\
\text { Maintain personal connection between } \\
\text { patients/family and research staff while }\end{array}$ \\
& Reduction in research pharmacy staff & maintaining social distancing \\
& & Consider patient/caregiver instructions by \\
email, telephone, and video & Consider patient home monitoring, e.g., blood \\
pressure and fingersticks mailed in & &
\end{tabular}

\begin{tabular}{ll}
\hline $\begin{array}{l}\text { Control group (best current standard } \\
\text { therapy or placebo) }\end{array}$ & As above for intervention \\
\hline $\begin{array}{ll}\text { Study population (enrollment, sample } \\
\text { size, and generalizability) }\end{array}$ & $\begin{array}{l}\text { Institutional policies vary related to suspension of research } \\
\text { and type of research suspended } \\
\text { Temporary halting of nonessential tests } \\
\text { Closure of outpatient clinics may adversely affect } \\
\text { identification of new cases potentially eligible for the trial }\end{array}$ \\
\hline
\end{tabular}

As above for intervention

Make study-wide decision to suspend new enrollment

Continue EMR screening activities to allow for rapid restart of recruitment

Plan widespread recruitment startup notifications and activities to referring physicians/patients

Outcome measures (end points, minimizing loss to follow-up, and adverse event monitoring)
Social distancing recommendations and quarantining orders Reduction in research staffing

Validation of potential end points requiring an in-person assessment and/or medical test

Outcome must be measured the same way in all participants Participant difficulty with virtual in-person health care encounters

Maintain personal connection between patients/family and research staff while maintaining social distancing

Consider structured telephone follow-up over in-person visits

Be prepared with staffing and funding to hit the ground running with in-person follow-up visits

Rereview with sites the manual of operations related to ascertainment of potential outcomes and adverse events

The protocol (who, what, when, and how)

Changes to protocol may be required, e.g., to allow telephone follow-up and/or virtual visits, extension of acceptable time windows, modifications to definitions of protocol deviations, etc.

Changes to case report forms may be required Additional complexity for FDA trials
Have early and more frequent regular communications with sites, including coordinators and PIs

Determine whether true protocol changes vs simply changes in manual of operations Early and regular communications with trial sponsor, external DSMB (and FDA if applicable)

Submit to central IRB first to be used as mode for single-site IRBs

Develop system for remote monitoring Early and regular communications with central
Informed consent process and
documentation and other regulatory

issues IRB

On-site monitoring suspended due to travel restrictions

Abbreviations: $\mathrm{DSMB}=$ Data and Safety Monitoring Board; EMR = electronic medical record; FDA = Food and Drug Administration; IRB = institutional review board; $\mathrm{PI}=$ principal investigator.

risk-based criteria (e.g., patients with stage 2 hypertension who are out of target at the last visit) for selecting patients to receive the same or similar automated blood pressure cuff as is used for in-clinic visits and training patients on its use. Selfmonitoring of blood pressure in conjunction with other strategies including medication titration by physicians has been shown to result in clinically significant and sustained blood pressure reduction. ${ }^{19}$ The database would distinguish home readings from in-clinic readings. We are also considering at-home methods for measurement of lipid profiles without the use of a phlebotomist, using validated fingerstickbased home-laboratory kits. In addition, for lifestyle-related risk factor counseling (e.g., for smoking, physical inactivity, and weight management), phone-based counseling services provided by INTERVENT will continue to be delivered without interruption.
A summary of the key elements of a clinical trial, the problems faced by the CREST-2 trial during the COVID-19 pandemic, and possible solutions are summarized in table 3 .

\section{Discussion}

COVID-19 has had remarkable social and economic effects across the United States and the world. The CREST-2 investigators immediately appreciated the adverse effects this pandemic was having on patient safety and the ability to continue the trial without adaptation of methods. The study has had to cope with making the difficult decision to temporarily suspend new enrollments at sites due to social distancing, quarantining, and cancelation of elective procedures, placing a primacy on patient safety. The American College of 
Surgeons has specifically recommended that asymptomatic carotid stenosis revascularization procedures be deferred under the current circumstances. ${ }^{20}$ Follow-up remains essential to preserve the scientific integrity of clinical trials. To this end, we have instituted telephone follow-up visits to ensure rigorous surveillance for end points. We have noted the remarkable level of teamwork of the research staff at the CCC, the SDCC, and across all sites to be certain that the trial achieves its aims as we emerge from this pandemic. This is made more notable in light of what would appear to be a research infrastructure under threat. Two-fifths of the research staff reported being redeployed to other tasks, and nearly one half are working at institutions that have had to furlough employees. The research infrastructure is not ideal either, with nearly one quarter of staff without remote access to source documentation if they were to work at home.

We are morally obligated to the patients previously randomized in the trial to use the information they have provided to inform the management of patients with asymptomatic extracranial atherosclerosis. As such, we did not consider premature stopping of the CREST-2 trial as an appropriate option. There is strong international consensus among ethics guidelines that research on human subjects must have scientific validity, including study design and statistical methods. ${ }^{21}$ Statistical power in a prevention trial is directly related to sample size and length of follow-up. We have an obligation to every patient in the trial to see that the question they are helping to answer gets answered unequivocally. In addition, asymptomatic carotid disease is extremely common in clinical practice, and completion of this trial is imperative to define the optimal management of these patients, thereby improving the care of these patients for many years to come.

\section{Acknowledgment}

The CREST-2 trials are supported by cooperative agreements U01 NS080168 and U01 NS080165 from the National Institute of Neurological Disorders and Stroke, NIH, and by the Centers for Medicare and Medicaid Services (CMS), Department of Health and Human Services. Additional support for CREST-2 comes from StrokeNet U01 NS086872. The authors thank the other investigators, the staff, and the participants of the CREST-2 trials for their valuable contributions. A full list of participating CREST-2 investigators and institutions can be found at crest2trial.org. The authors thank Ms. Kassondra Guzman and Mrs. Sothear Luke for technical assistance with the online surveys and Mrs. Colleen McLeod for assistance with the process of submitting the manuscript.

\section{Study funding}

CREST-2 is funded by grants from the National Institute of Neurological Disorders and Stroke (U01NS080168 and U01NS080165).

\section{Disclosure}

The authors report no relevant disclosures. Go to Neurology. org/ $\mathrm{N}$ for full disclosures.

\section{Publication history}

Received by Neurology April 1, 2020. Accepted in final form April 27, 2020.

Appendix Authors

\begin{tabular}{|c|c|c|}
\hline Name & Location & Contribution \\
\hline $\begin{array}{l}\text { James F. } \\
\text { Meschia, } \\
\text { MD }\end{array}$ & $\begin{array}{l}\text { Mayo Clinic Jacksonville, } \\
\text { Florida }\end{array}$ & $\begin{array}{l}\text { Co-principal investigator } \\
\text { for the CREST-2 Clinical } \\
\text { Coordinating Center; } \\
\text { conceived the study; helped } \\
\text { draft surveys; analyzed } \\
\text { data; and drafted and } \\
\text { revised the manuscript. }\end{array}$ \\
\hline $\begin{array}{l}\text { Kevin M. } \\
\text { Barrett, } \\
\text { MD }\end{array}$ & $\begin{array}{l}\text { Mayo Clinic Jacksonville, } \\
\text { Florida }\end{array}$ & $\begin{array}{l}\text { Co-principal investigator } \\
\text { for the CREST-2 Clinical } \\
\text { Coordinating Center; } \\
\text { conceived the study; helped } \\
\text { draft surveys; analyzed } \\
\text { data; and drafted and } \\
\text { revised the manuscript. }\end{array}$ \\
\hline $\begin{array}{l}\text { Robert D. } \\
\text { Brown, Jr, } \\
\text { MD }\end{array}$ & $\begin{array}{l}\text { Mayo Clinic, Rochester, } \\
\text { Minnesota }\end{array}$ & $\begin{array}{l}\text { Drafted and revised the } \\
\text { manuscript. }\end{array}$ \\
\hline $\begin{array}{l}\text { Tanya N. } \\
\text { Turan, MD }\end{array}$ & $\begin{array}{l}\text { Medical University of South } \\
\text { Carolina, Charleston, South } \\
\text { Carolina }\end{array}$ & $\begin{array}{l}\text { Drafted and revised the } \\
\text { manuscript. }\end{array}$ \\
\hline $\begin{array}{l}\text { Virginia J. } \\
\text { Howard, } \\
\text { PhD }\end{array}$ & $\begin{array}{l}\text { University of Alabama at } \\
\text { Birmingham }\end{array}$ & $\begin{array}{l}\text { Drafted and revised the } \\
\text { manuscript and tables. }\end{array}$ \\
\hline $\begin{array}{l}\text { Jenifer H. } \\
\text { Voeks, } \\
\text { PhD }\end{array}$ & $\begin{array}{l}\text { Medical University of South } \\
\text { Carolina, Charleston, South } \\
\text { Carolina }\end{array}$ & $\begin{array}{l}\text { Analyzed survey data and } \\
\text { drafted and revised the } \\
\text { manuscript. }\end{array}$ \\
\hline $\begin{array}{l}\text { Brajesh K. } \\
\text { Lal, MD }\end{array}$ & University of Maryland & $\begin{array}{l}\text { Co-principal investigator } \\
\text { for the CREST-2 Clinical } \\
\text { Coordinating Center; } \\
\text { conceived the study; helped } \\
\text { draft surveys; analyzed } \\
\text { data; and drafted and } \\
\text { revised the manuscript. }\end{array}$ \\
\hline $\begin{array}{l}\text { George } \\
\text { Howard, } \\
\text { DrPH }\end{array}$ & $\begin{array}{l}\text { University of Alabama at } \\
\text { Birmingham }\end{array}$ & $\begin{array}{l}\text { Principal investigator of the } \\
\text { CREST-2 Statistical and Data } \\
\text { Monitoring Center and } \\
\text { drafted and revised the } \\
\text { manuscript }\end{array}$ \\
\hline $\begin{array}{l}\text { Thomas G. } \\
\text { Brott, MD }\end{array}$ & $\begin{array}{l}\text { Mayo Clinic Jacksonville, } \\
\text { Florida }\end{array}$ & $\begin{array}{l}\text { Co-principal investigator } \\
\text { for the CREST-2 Clinical } \\
\text { Coordinating Center; } \\
\text { helped draft surveys; } \\
\text { analyzed data; and drafted } \\
\text { and revised the manuscript. }\end{array}$ \\
\hline
\end{tabular}

\section{References}

1. Zhou P, Yang XL, Wang XG, et al. A pneumonia outbreak associated with a new coronavirus of probable bat origin. Nature 2020;579:270-273.

2. Holshue ML, DeBolt C, Lindquist S, et al. First case of 2019 novel coronavirus in the United States. N Engl J Med 2020;382:929-936.

3. Murray CJL. Forecasting COVID-19 impact on hospital bed-days, ICU-days, ventilator days and deaths by US state in the next 4 months. IMHE web page. Avaiable at: healthdata.org/research-article/forecasting-covid-19-impact-hospital-bed-days-icudays-ventilator-days-and-deaths. Accessed April 2, 2020.

4. Trachtman H, Caplan A. Data monitoring committees and stopping trials-giving participants a voice. Contemp Clin Trials 2018;68:146.

5. Cassileth BR, Lusk EJ, Miller DS, Hurwitz S. Attitudes toward clinical trials among patients and the public. JAMA 1982;248:968-970. 
6. Howard V, Meschia JF, Lal BK, et al. Carotid revascularization and medical management for asymptomatic carotid stenosis: protocol of the CREST-2 clinical trials. Int J Stroke 2017;12:770-778.

7. Livingston E, Bucher K. Coronavirus disease 2019 (COVID-19) in Italy. JAMA 2020; 323:1335.

8. Bialek S, Boundy E, Bowen V, et al. Severe outcomes among patients with coronavirus disease 2019 (COVID-19) —United States, February 12-March 16, 2020. MMWR 2020;69:343-346.

9. Fang L, Karakiulakis G, Roth M. Are patients with hypertension and diabetes mellitus at increased risk for COVID-19 infection? Lancet Respir Med 2020;8:E21.

10. Jordon RE. COVID-19 risk factors for severe disease and death. BMJ 2020;368:m1198.

11. Yan R, Zhang Y, Li Y, Xia L, Guo Y, Zhou Q. Structural basis for the recognition of SARS-CoV-2 by full-length human ACE2. Science 2020;367:1444-1448.

12. Available at: newsroom.heart.org/news/patients-taking-ace-i-and-arbs-who-contractcovid-19-should-continue-treatment-unless-otherwise-advised-by-their-physician. Accessed March 31, 2020

13. Mahase E. COVID-19: UK starts social distancing after new model points to 260,000 deaths. BMJ 2020;368:m1089.

14. Ferguson NM, Laydon D, Nedjati-Giani G, et al. Report 9: Impact of Nonpharmaceutical Interventions (NPIs) to Reduce COVID-19 Mortality and Healthcare
Demand. Imperial College London; 2020. Available at: imperial.ac.uk/mrc-globalinfectious-disease-analysis/news-wuhan-coronavirus/. Accessed on May 14, 2020.

15. Kang L, Li Y, Hu S, et al. The mental health of medical workers in Wuhan, China dealing with the 2019 novel coronavirus. Lancet Psychiatry 2020;7:e14.

16. Meschia JF, Brott TG, Chukwudelunzu FE, et al. Verifying the stroke-free phenotype by structured telephone interview. Stroke 2000;31:1076-1080.

17. Bruno A, Akinwuntan AE, Lin C, et al. Simplified modified Rankin scale questionnaire: reproducibility over the telephone and validation with quality of life. Stroke 2011;42:2276-2279.

18. Warttig SL, Forshaw MJ, South J, White AK. New, normative, English-sample data for the Short Form Perceived Stress Scale (PSS-4). J Health Psychol 2013;18: $1617-1628$.

19. Tucker KL, Sheppard JP, Stevens R, et al. Self-monitoring of blood pressure in hypertension: a systematic review and individual patient data meta-analysis. PLoS Med 2017; 14:e1002389.

20. Available at: facs.org/covid-19/clinical-guidance/elective-case/vascular-surgery. Accessed on May 14, 2020.

21. Bernabe RD, van Thiel GJ, van Delden JJ. What do international ethics guidelines say in terms of the scope of medical research ethics? BMC Med Ethics 2016;17:23.

\section{New, Free Mobile Learning App Offers Complimentary Self-assessment CME}

The American Academy of Neurology is pleased to offer a new, mobile educational resource-free to AAN members! The Neurology Question of the Day mobile app offers a quick, convenient, and fun way to assess your knowledge and fulfill selfassessment CME requirements. Get started at AAN.com/QODapp.

\section{Subspecialty Alerts by E-mail!}

Customize your online journal experience by signing up for e-mail alerts related to your subspecialty or area of interest. Access this free service by clicking on the "My Alerts" link on the home page. An extensive list of subspecialties, methods, and study design choices will be available for you to choose from-allowing you priority alerts to cutting-edge research in your field!

\section{Call for Voices: Lived Experiences}

The Editors of the Neurology specialty site Equity, Diversity, \& Inclusion encourage you to submit short first-person accounts (1,000 words or less) of experiences lived within the realm of equity, diversity, and inclusion (EDI) with the goal of informing and enlightening our community on these critical issues. Some topics to consider include, but are not limited to:

- Descriptions of personal experiences that shaped your views of EDI.

- Reflections on the intersection between personal identity and career.

- Discussions at the intersection of EDI and neurology patient care, research, education, advocacy, or policy.

Submit your contributions to journal@neurology.org and include "Voices Submission" in the subject line. 


\section{Neurology}

\section{The CREST-2 experience with the evolving challenges of COVID-19: A clinical trial in a pandemic}

James F. Meschia, Kevin M. Barrett, Robert D. Brown, Jr, et al.

Neurology 2020;95;29-36 Published Online before print May 1, 2020

DOI 10.1212/WNL.0000000000009698

This information is current as of May 1, 2020

\section{Updated Information \&} Services

References

Subspecialty Collections

Permissions \& Licensing

Reprints including high resolution figures, can be found at: http://n.neurology.org/content/95/1/29.full

This article cites 17 articles, 5 of which you can access for free at: http://n.neurology.org/content/95/1/29.full\#ref-list-1

This article, along with others on similar topics, appears in the following collection(s):

\section{All Clinical trials}

http://n.neurology.org/cgi/collection/all_clinical_trials

Other cerebrovascular disease/ Stroke

http://n.neurology.org/cgi/collection/other_cerebrovascular_disease_st roke

Stroke prevention

http://n.neurology.org/cgi/collection/stroke_prevention

Information about reproducing this article in parts (figures,tables) or in its entirety can be found online at:

http://www.neurology.org/about/about_the_journal\#permissions

Information about ordering reprints can be found online:

http://n.neurology.org/subscribers/advertise

Neurology ${ }^{\circledR}$ is the official journal of the American Academy of Neurology. Published continuously since 1951, it is now a weekly with 48 issues per year. Copyright (C 2020 American Academy of Neurology. All rights reserved. Print ISSN: 0028-3878. Online ISSN: 1526-632X.

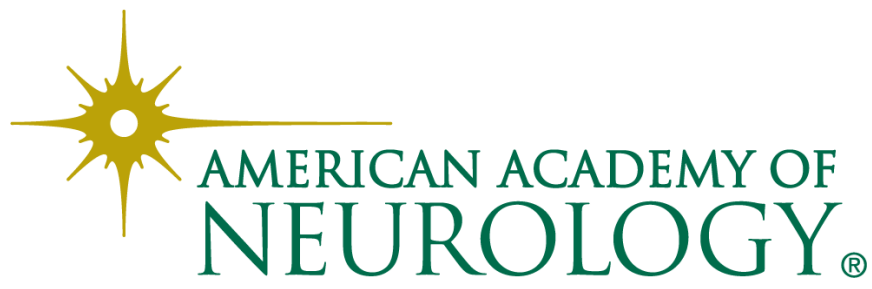

